\title{
GaAs MEMS for Millimeter Wave Communications
}

\author{
Alexandru Muller ${ }^{1}$, George Konstantinidis ${ }^{2}$, Dan Neculoiu ${ }^{1}$ and Robert Plana ${ }^{3}$ \\ ${ }^{1}$ IMT Bucharest, 32B, Erou Iancu Nicolae Street, 72996, Bucharest, Romania, Phone: +40.21 .4908581$ \\ ${ }^{2}$ FORTH-IESL-MRG, PO Box 1527, Heraklion, Greece, Phone: +30.2810 .394103$ \\ ${ }^{3}$ LAAS-CNRS Toulouse, 7, Av Colonel Roche, 31077 Toulouse, Cedex 4, France, Phone: +33.5 .61336371$
}

\begin{abstract}
The paper presents the authors' contributions towards the development of millimeter wave circuits based on GaAs micromachining. The manufacturing and characterization of different type of millimeter wave GaAs membrane supported filter structures is presented. A fully monolithically integrated millimeter wave receiver module, having the antenna as well as the detecting Schottky diode on the same GaAs membrane is also presented.
\end{abstract}

\section{INTRODUCTION}

The continuous sharp growth in the number of communication systems users leads to an overcrowded frequency spectrum thus resulting into a continuous increase in the value of the allocated frequencies. Moreover, it is very difficult to deliver passive devices (inductors, capacitors, transmission lines, filters and antennae) featuring low loss and high quality factor in the millimeter wave range, using classical technologies, due to losses (dielectric, conductive and substrate modes). One emerging solution exploits the micromachining capabilities of semiconductor materials. The use of micromachining techniques has as its main effect the substantial reduction of losses in the millimeter wave range due to the substrate removal. Additional beneficial effects are the reduction of dispersion effects, the suppression of higher substrate modes and the possibility of using higher transmission line characteristic impedance values in the design. These improvements are due mainly to the fact that a very thin dielectric or high resistivity semiconductor membrane, used as support for passive circuit elements (inductors, capacitors, transmission lines, filters antennae), reduces the effective permittivity to values very close to 1 . These elements look like being "air suspended". The technology of membrane supported microwave passive circuit elements based on silicon micromachining was initially developed about ten years ago, at Ann Arbor Univ. Michigan [1,2].

Micromachining of GaAs is an exciting less explored alternative for manufacturing of components and modules for high performance communication systems. GaAs micromachining is very interesting for the RFMEMS field also due to the easy monolithic integration of micromachined passive circuit elements with active devices manufactured on the same chip.

The MBE or MOCVD epitaxy grown layers of III-V compound semiconductor heterostructures provide flexibility and precision in micromachining. These layers are sharp and due to different composition they can be etched by wet or dry techniques with excellent selectivity. The system $\mathrm{GaAs} / \mathrm{Al}_{\mathrm{x}} \mathrm{Ga}_{1-\mathrm{x}} \mathrm{As}$ can be used this purpose. Some dry and wet etching systems exhibit etching rates of GaAs orders of magnitude higher than for $\mathrm{Al}_{\mathrm{x}} \mathrm{Ga}_{1-\mathrm{x}} \mathrm{As}$ and vice versa (if $\mathrm{x} \geq 0.5$ ). Most commonly AlGaAs is used as an etch stop layer for GaAs. A lot of selective wet etching solutions for the GaAs/AlGaAs system were reported [3-5], but the best and reproducible results were obtained using dry etching systems. Using the GaAs/AlGaAs heterostructure and the etch stop properties of AlGaAs with respect to GaAs, pressure, power, and thermoelectric sensors were reported [6-8]. The typical thickness of the GaAs membranes for this type of sensing structures is about $1 \mu \mathrm{m}$ and the thickness of the etch-stop AlGaAs layer is about $0.2 \mu \mathrm{m}$. Millimeter wave filter structures supported on GaAs membranes were manufactured in the last years by groups involving the authors of this paper [9-10]. Substrateless Schottky diodes, for applications in the terahertz frequency range, were also recently reported [11-12]. These diodes have as main advantages the reduction of series resistance, less influence of skin effect, quasi vertical current flow and increase of power handling capabilities. A monolithically integration of an antenna with a Schottky diode, on the same thin GaAs membrane, in a millimeter wave receiver module was recently reported by the authors of this paper [13]. Some circuits for applications in the terahertz frequency range, based on GaAs micromachining, were also recently reported and are described in [14]. This paper will present some contributions of the authors in the developing of millimeter wave circuits based on GaAs micromachining. The paper is organized as follows: section II presents the manufacturing and measurements of GaAs membrane supported folded stub filters structures, designed for 38 and $77 \mathrm{GHz}$ operating frequency, section III presents the manufacturing and measurements for a new type of membrane supported coupled line filter, designed for $45 \mathrm{GHz}$ operating frequency, section IV presents the manufacturing and measurements of a monolithically integrated receiver module, supported on a thin GaAs membrane. Finally, conclusions are outlined in the last section.

\section{GaAs Membrane SupPorted MiLlimeter WAVE FOLDED STUB FILTERS}

In the design of the first GaAs membrane supported band pass filters we have manufactured, it was considered a four cascaded/opposite double folded open end series stubs geometry for the $38 \mathrm{GHz}$ filter. For the 
$77 \mathrm{GHz}$ filter structure, the design was based on a four cascaded standard coplanar waveguide (CPW) open end series stubs, non-folded, due to the lower length of the quarter wavelength stubs.

Conventional and Low Temperature III-V MBE growth was used to fabricate the $\mathrm{GaAs} / \mathrm{AlGaAs} / \mathrm{GaAs}$ heterostructure. Semiinsulating GaAs wafers $\left(\rho=10^{7}\right.$ $\Omega \mathrm{cm}$ ), with a thickness of $460 \mu \mathrm{m}$, were used as substrate. The MBE process started with a very thin (50nm) buffer GaAs layer deposition. Over this layer, a $0.2 \mu \mathrm{m}$ thin $\mathrm{Al}_{\mathrm{x}} \mathrm{Ga}_{1-\mathrm{x}} \mathrm{As}$ etch stop layer (with $\mathrm{x}=0.6$ ) was deposited. Over the AlGaAs layer, a low temperature (LT) seminsulating $2^{\circ} \mu \mathrm{m}$ thin GaAs layer $\left(\rho>10^{6} \Omega \mathrm{cm}\right)$ was deposited. The growth experiments were performed in a VG80 horizontal MBE chamber with a background pressure of $10^{-10}$ mbar. During growth, the chamber pressure was $10^{-7}$ mbar.

Conventional contact lithography, e-gun evaporation and lift-off techniques were used to define the filter structure. A $500 \AA \mathrm{Ti} / 7000 \AA \mathrm{Au}$ metallization was used, then the wafers were mounted face-down on special glass plates and the GaAs substrate was thinned down to $150 \mu \mathrm{m}$ by lapping technique.

The etching pattern for the membranes was defined by backside alignment contact photolithography. The membranes were fabricated in a Vacutec 1350 RIE chamber using $\mathrm{CCl}_{2} \mathrm{~F}_{2}$. End point detection and optical (visual) detection was used during the RIE etching. After the selective etching, the thickness is approximately $2.2 \mu \mathrm{m}$. A SEM photo of the $77 \mathrm{GHz}$ GaAs membrane supported filter structure is presented in Fig. 1. In Fig. 2 (left) it is presented a top view of the $38 \mathrm{GHz}$ filter structure. The GaAs membrane is visible by transparency. A white light interferometric analysis of the GaAs membrane supported filter structure is presented also in Fig. 2 (right). The deflection has a maximum value of about 3 $\mu \mathrm{m}$, in vicinity of the folded stubs. The membrane area was about $2 \times 6 \mathrm{~mm}^{2}$.

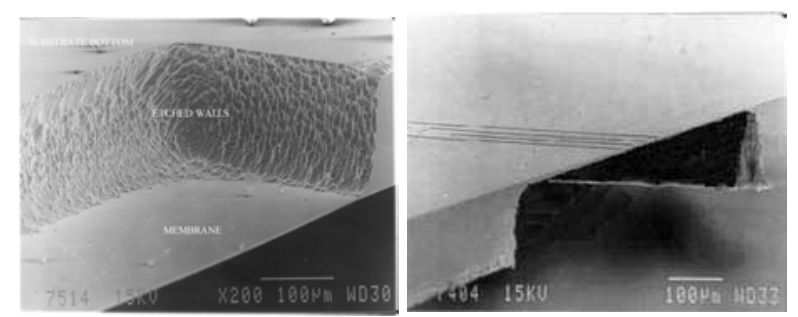

Fig. 1. SEM photos of a GaAs membrane supporting a 77 $\mathrm{GHz}$ open end series stub filter structure (bottom view-left, top view-right)

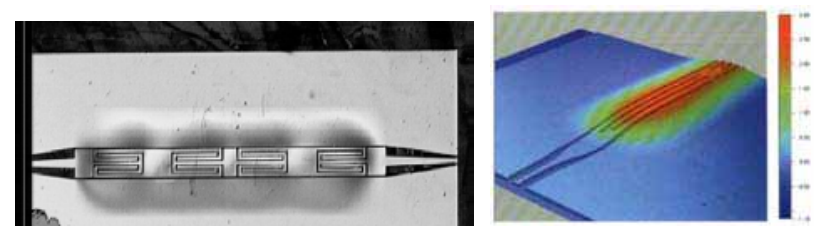

Fig. 2 Top photo of a GaAs membrane supported folded stub filter structure for $38 \mathrm{GHz}$ (left) and white light interferometric analysis of the structure (right)
The microwave measurements were performed using an on-wafer measuring set-up equipped with Cascade Microtech coplanar probes (with working frequency ranges of $0-50 \mathrm{GHz}$ and $70-110 \mathrm{GHz}$, respectively) and HP 8510 network analyzer. The $\mathrm{S}$ parameter measurements for $38 \mathrm{GHz}$ based band-pass filters are presented in Fig. 3. The $38 \mathrm{GHz}$ filter characteristics exhibited about $1.46 \mathrm{~dB}$ insertion loss at $38 \mathrm{GHz}$ and a maximum return loss of $34.2 \mathrm{~dB}$ at $36.4 \mathrm{GHz}$. The 77 $\mathrm{GHz}$ filter responses exhibited a minimum insertion loss of $1.87 \mathrm{~dB}$ at $72.4 \mathrm{GHz}$ and a maximum return loss of $17.4 \mathrm{~dB}$ at $74.8 \mathrm{GHz}$. There is a fairly good agreement between the measured and the calculated characteristics of the filter structures, less than $3.4 \%$ between the measured and design values as concerns the band-pass central frequencies.

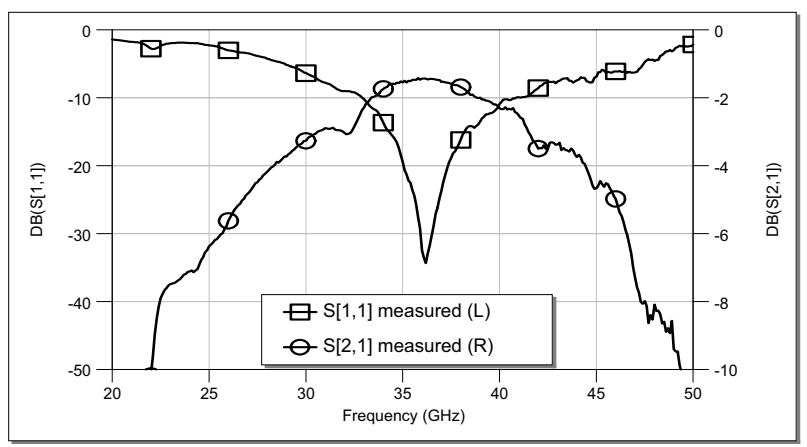

Fig. 3. S parameter measurements for the GaAs membrane supported folded stub filter structure for $38 \mathrm{GHz}$

\section{GaAs Membrane Supported Millimeter WAVE COUPLED LINE FILTER STRUCTURES}

A similar technological process as that described in the previous section was used to manufacture a new high performance band pass filter structure. The filter consists of a number of identical cells connected in cascade, each cell containing two single line sections and one coupled line section of CPW transmission line. The design method was similar with that presented in [15] and was based on image parameter representation of the two-port networks.

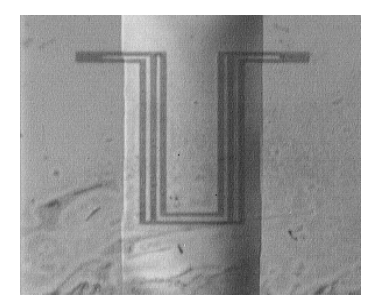

Fig. 4. Top photo of a GaAs membrane supported coupled line filter structure, designed for $45 \mathrm{GHz}$ operating frequency

A top photo of a two-cell filter structure, designed for $45 \mathrm{GHz}$ central operating frequency is presented in Fig.4. A comparison between the experimental and simulated results for filter [S] parameters is presented in Fig.5 and the agreement is very good. Insertion losses lower then 
$0.8 \mathrm{~dB}$ in the band pas were obtained. On the same wafer, test structures for the characterization of the GaAs membrane supported CPW lines were manufactured. Using the measured [S] parameters of two CPW lines with different length, it was possible to extract the broadband value of the CPW effective permitivity. The experimental results are shown in Fig. 6 and are compared with the simulated effective permittivity. The very good agreement validates the quality of the technological process as well as the design methodology used for these types of components.

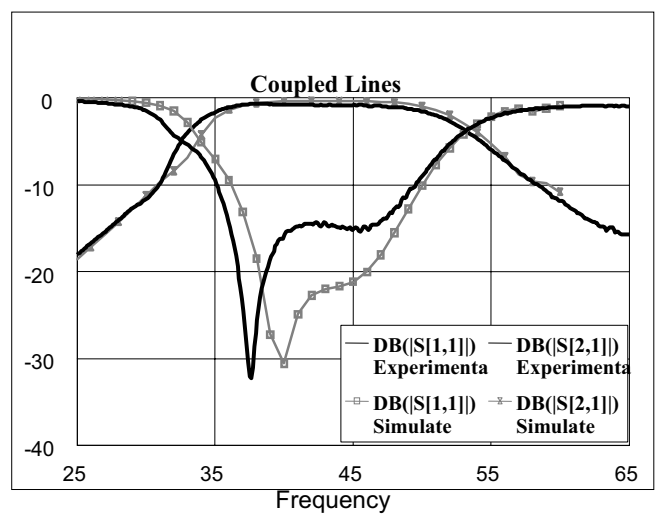

Fig. 5. Computed and measured $\mathrm{S}$ parameters for the $45 \mathrm{GHz}$ GaAs membrane supported coupled line filter structure

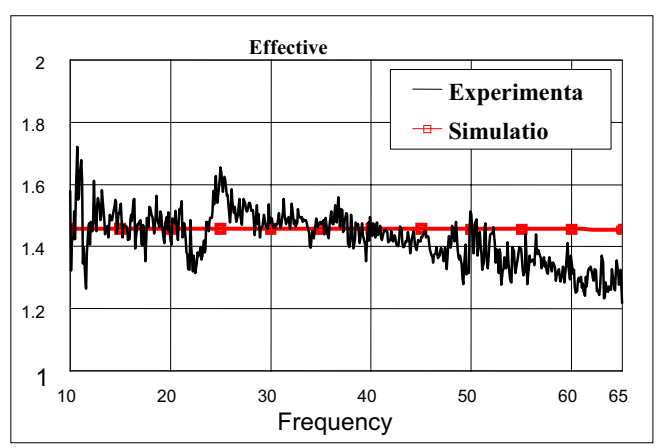

Fig. 6. Experimental determination of $\varepsilon_{\text {eff }}$

\section{GaAs Membrane Supported Millimeter WaVe RECEIVER STRUCTURES}

In this chapter we will describe the monolithic integration of a Schottky diode with an antenna, on the same thin GaAs membrane, for millimeter wave receiving applications. The area of the monolithically integrated GaAs Schottky diode can be reduced to dimensions limited only by technology. The cut-off frequency can be increased to the terahertz range. The receiver module, at this stage, was designed and manufactured for the $38 \mathrm{GHz}$ operating frequency. The MBE structure for the micromachined receiver module is the following: on a semi-insulating GaAs substrate, a $0.2 \mu \mathrm{m}$ thin $\mathrm{Al}_{\mathrm{x}} \mathrm{Ga}_{1-\mathrm{x}} \mathrm{As}$ layer with $\mathrm{x}>0.55$ was grown (the etch-stop layer) and over it, a $2 \mu \mathrm{m} \mathrm{LT} \mathrm{GaAs} \mathrm{layer}$ (the membrane layer). Following, two layers - $0.5 \mu \mathrm{m}$ GaAs, $1 * 10^{18} \mathrm{~cm}^{-3}$ and $0.5 \mu \mathrm{m} \mathrm{GaAs} 1 * 10^{17} \mathrm{~cm}^{-3}$ were grown. These layers are necessary for the Schottky diode formation. The MBE structure is presented in Fig .7

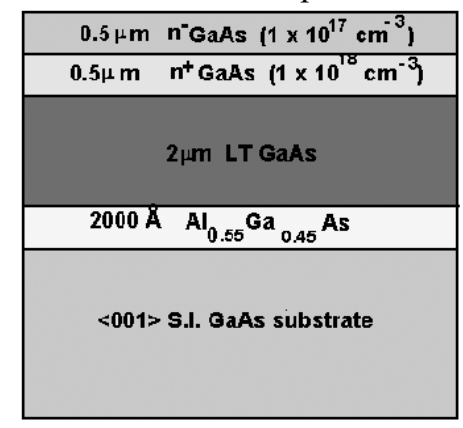

Fig. 7. The MBE structure for the micromachined receiver

First the two mesas were formed. The first mesa was a $10 \times 10 \mu \mathrm{m}^{2}$ square on the $\mathrm{n}$ layer on which the Schottky diode was fabricated during the final stage of the process. The second mesa $\left(36 \times 36 \mu \mathrm{m}^{2}\right)$ surrounds the first one and reached the $n+$ layer to facilitate the ohmic contact formation. Dry etching process (RIE) based on $\mathrm{Cl}_{2}$ and $\mathrm{BCl}_{3}$ chemistry, resulted in $0.6 \mu \mathrm{m}$ etched depth, for both mesas. Rapid thermally annealed ([Ge/Au]x4/Ni/Au with a total thickness of $0.2 \mu \mathrm{m})$ metallization formed the "ohmic arm" of the antenna, which over-crosses the second mesa area on one side, to form the ohmic contact of the Schottky diode. The ohmic metallization was thickened up to $1 \mu \mathrm{m}$ by gold evaporation using a separate mask. For the "Schottky arm" of the antenna, $\mathrm{Ti} / \mathrm{Pt} / \mathrm{Au}$ metallization was used. The most demanding step in our process was to form the Schottky contact of the diode and to connect it with the "Schottky arm", by over-crossing the $\mathrm{n}^{+}$layer on a polyimide bridge. The polyimide layer, $3 \mu \mathrm{m}$ thick, was spun over the wafer and patterned. The polyimide-bridge over-crosses the first mesa by $3 \mu \mathrm{m}$ and the second mesa completely towards the Schottky arm direction. After patterning and curing, the polyimide thickness became $2.5 \mu \mathrm{m}$. The Schottky metallization of the diode (TiPtAu) was inter-connected with the Schottky antenna arm over-crossing the polyimide-bridge. This is a difficult step due to the small area of the diode and the relative big steps to be overcrossed by resist and metal. All metallization were performed using lift-off techniques. Before the last mask (backside-alignment for membrane formation) the wafer was lapped down to $150 \mu \mathrm{m}$. Selective RIE process with $\mathrm{CCl}_{2} \mathrm{~F}_{2}$ and end point and optical detection were used for the formation of the membrane. The area of the membrane was $5.85 \times 4.5 \mathrm{~mm}^{2}$.

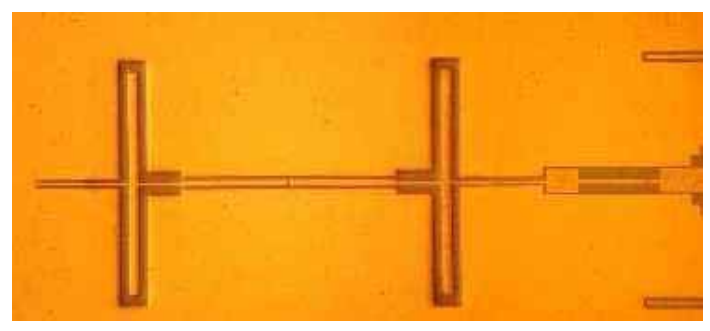

Fig. 8. Top photo of the $38 \mathrm{GHz}$ micromachined receiver 
A top photo of the receiver structure is presented in Fig. 8 and a SEM photo with a detailed view of the Schottky diode region is presented in Fig. 9. Starting from a $4 \times 4 \mathrm{~m}^{2}$ square on the mask, a quasi-circular diode with an estimated area of about $11 \mu \mathrm{m}^{2}$ was finally obtained.

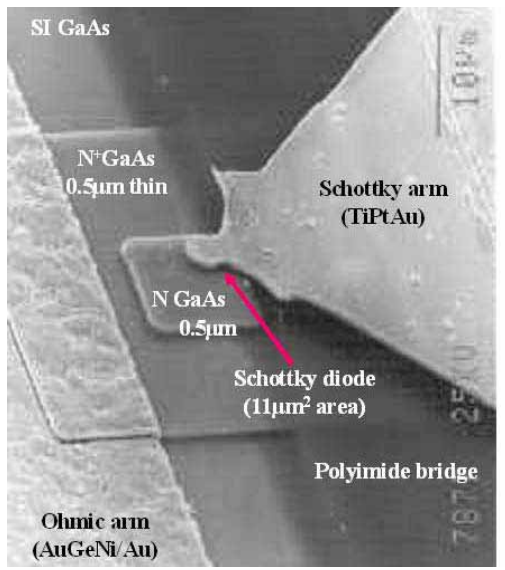

Fig. 9. Blow-up of the integrated Schottky diode region (SEM photo)

The Schottky diode parameters were determined by DC and microwave measurements. From the I-V curves obtained by "on wafer" measurements, the following parameters were estimated: $\Phi_{\mathrm{B}}=0.68-0.7 \mathrm{~V}, \mathrm{R}_{\mathrm{s}}=20-22$ ohm, $\mathrm{n}=1.25-1.31$ and $\mathrm{I}_{\mathrm{s}}=7 \times 10^{-14}-1 \times 10^{-13} \mathrm{~A}$. The estimated value for the zero bias capacitance of about $10 \mathrm{fF}$ was confirmed by microwave measurements.

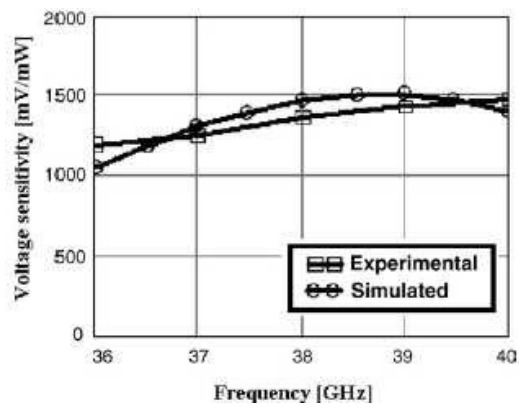

Fig.10. Receiver voltage sensitivity (simulated and measured)

The receiver structures were characterized in the millimeter wave frequency range. In Fig 10 there are presented the measured and the simulated values for the voltage sensitivity of the receiver structure when the diode is forward biased at $0.1 \mathrm{~mA}$ and in Fig 11 it is presented a comparison between the simulated and measured radiation pattern of the antenna.

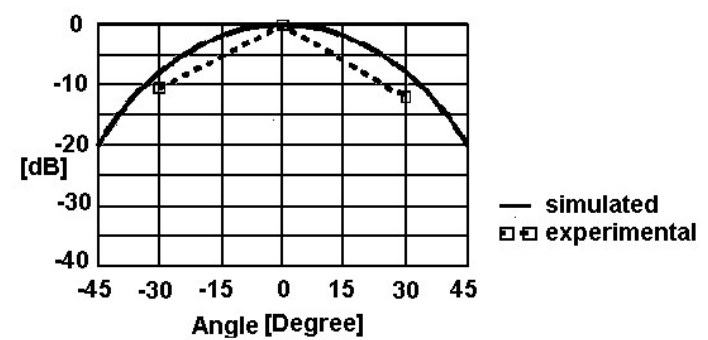

Fig.11. Receiver radiation pattern (simulated and measured)

\section{CONCLUSIONS}

Novel micromachined millimeter wave circuits, based on GaAs micromachining were manufactured. GaAs membrane supported filter structures with losses lower then $0.8 \mathrm{~dB}$ at $45 \mathrm{GHz}$ were obtained. High performance monolithically integrated millimeter wave receiver modules having the antenna as well as the Schottky diode on the same GaAs membranes were manufactured.

\section{REFERENCES}

[1] T. M. Weller, G. M. Rebeiz and L.P.B Katehi "Experimental results in microshield transmission line circuits" IEEE-MTT-S International Simposium Digest vol 2, pp 827-830, 1993

[2] R. F. Drayton G. M. Rebeiz and L.P.B. Katehi "Development of miniature microwave circuit components using micromachining techniques IEEE-MTT-S International Simposium Digest vol 1, pp 225-228, 1992

[3] K. Hjort "Gallium Arsenide micromechanics - A comparation to silicon and quartz"- Proc. of GaAs Applications Symposium, Torino, pp. 65-72, 1994.

[4] K. Hjort "Micromachining of non-silicon materials", NEXUS Workshop on Micro-Machining, IMSAS, Univ. Bremen, pp. 1-18, May 1995.

[5] K. Hjort "Sacrificial etching of III-V compounds for micromechanical devices", J. Micromech. Microeng., no. 6, pp.370-375, 1996.

[6] A. Dehe, D. Pavlidis, K. Hong, H.L. Hartnagel "InGaAs/InP Thermoelectric infrared sensor utilizing surface bulk micromachining technology", IEEE Trans. on Electron Devices, vol. 44, pp. 1052-1056, July 1997.

[7] K. Frike A. Dehe, M. Schusller, W Y Lee and H.L. Hartnagel, "Micromechanical sensors based on GaAs:AlGaAs" Proc. of GaAs Applications Symposium, Torino, pp. 65-72, 1994

[8] T. Lalinsky et al. "Micromachined power sensor microsystem", Proc. $9^{\text {th }}$ Micromechanics Europe Workshop MME'98, Ulvik in Hardanger, Norway, pp.139143, June 1998 ,

[9] A. Muller, G. Konstantinidis, F. Giaccomozzi, M. Lagadas, G. Deligeorgis, S. Iordanescu, I. Petrini, D. Vasilache, R.Marcelli, G. Bartolucci, D. Neculoiu, C. Buiculescu, P. Blondy, D. Dascalu. "Micromachined filters for 38 and $77 \mathrm{GHz}$ supported on thin membranes", J. Micromech. Microeng. vol.11, pp. 1-5, 2001

[10] G. Konstantinidis, A Muller et al. "GaAs membrane supported millimeter wave filters", Proceeding of SPIE, San Francisco, vol. 4559, pp 157-161, Oct. 2001

[11] P.H. Siegel, R.P. Smith, S. Martin, M. Gaidans "2.5-THz GaAs Monolithic Membrane-Diode Mixer" IEEE, Trans. Microwave.Theory Tech, Vol.47, pp.596-604, May 1999

[12] V. Ichizli, M. Rodriguez-Girones, C-I. Lin, P. Szeliga and H. L. Hartnagel "The Effect of Gas Plasma on the Deposition Quality of Schottky Metals and Interconnect Metallization for Planar Diodes Structure for $\mathrm{THz}$ Applications", $9^{\text {th }}$ intern. Conf. on $\mathrm{THz}$ Electronics, Charlottesville, Virginia, Oct. 2001

[13] G Konstantinidis D Neculoiu M Lagadas G Deligiorgis D Vasilache and A Muller "GaAs membrane supported millimeter-wave receiver structures", J. Micromech. Microeng. vol.13, pp 353-358, 2003

[14] P Siegel "Terahertz Technology", IEEE Trans on Micowave Theory and Techniques vol 50 pp 910-928

[15] G.Bartolucci, D.Neculoiu, M.Dragoman, F.Giacomozzi, R.Marcelli, A.Muller, "Modeling, Design and Characterization of Micromachined Millimeter Wave Band-pass Filters", Int. J. of Circuit Theory an Applications, 2003, in press 